\title{
Perfil ocupacional y estrategias de actuación profesional de trabajadores sociales en el contexto paraguayo ${ }^{a}$
}

\section{Labor profile and social work intervention in the context of Paraguay}

\author{
Mónica Ruoti Cosp ${ }^{b}$
}

\begin{abstract}
Resumen
Se describe el perfil ocupacional y la actuación profesional de trabajadores sociales en el contexto paraguayo, que constituyen dos dimensiones abordadas en un trabajo de Tesis realizada en el marco de una Maestría en Trabajo Social (UA).

Estudio descriptivo cuantitativo. Se realizó una encuesta autosuministrada a 164 profesionales Trabajo social. La gran mayoría se halla trabajando en instituciones públicas, principalmente en los campos de salud, educación y bienestar social y un bajo porcentaje lo ejerce de manera independiente. Las características que asume su práctica hacen que su campo de acción sea muy amplio y variado, identificando un amplio listado de campos de intervención. Se trabaja con familias, mujeres, jóvenes, adultos mayores, infancia, discapacitados y funcionarios. Más de la mitad utiliza métodos tradicionales y la mayoría realiza atención directa y a nivel micro. La mayoría de los profesionales participan en equipos interdisciplinarios. Un bajo porcentaje percibe la existencia de un proyecto ético político en el país. La principal dificultad que enfrenta en su quehacer profesional, están relacionadas con los aspectos institucionales.
\end{abstract}

Palabras clave: trabajo social, perfil laboral, intervención profesional, campos, funciones.

\footnotetext{
Abstract

The article addresses labor and professional performance aspects in the Paraguayan context. It presents two dimensions studied within a Master in Social Work. Quantitative descriptive study. A survey was given to 164 Social Work professionals. The vast majority is working in public institutions, mainly in the fields of health, education and social welfare and a low percentage is working independently. The practice characteristics make its field of action very broad and varied, identifying a wide range of intervention fields. We work with families, women, young people, the elderly, children, disabled
}

Kera Yvoty: reflexiones sobre la cuestión social. Vol. 2, 2017, 28-40.

ISSN (impreso): 2519-7797

a Se presenta parte de una investigación realizada como Tesis de la Maestría en Trabajo Social cursada en la Universidad Americana, Paraguay.

En el presente artículo no se utilizará lenguaje de géneros diferenciados por lo que se hablará del profesional trabajador social en forma genérica.

b Universidad Nacional de Asunción, Instituto de Trabajo Social, Paraguay. Universidad Técnica de Comercialización y Desarrollo, Facultad de Trabajo Social, Paraguay. Universidad Iberoamericana, Dirección de Investigación, Paraguay.

Correspondencia a: monicaruoti@gmail.com

Cita:

Ruoti, M. (2017). Perfil ocupacional y estrategias de actuación profesional de trabajadores sociales en el contexto paraguayo. Kera Yvoty: reflexiones sobre la cuestión social, 2, 44-56.

Recibido:

19 noviembre de 2017

Aceptado:

28 diciembre 2017 
and civil servants. More than half use traditional methods and most of them perform direct and micro-level attention. Most professionals participate in interdisciplinary teams. A low percentage perceives the existence of a political ethical project in the country. The main difficulty they faces in his professional work is related to the institutional.

Keywords: social work, job profilem, professional intervention, fields, functions.

\section{Introducción}

El proceso de profesionalización del Trabajo Social ha adquirido madurez en las últimas décadas y ha sido construida en un marco de rupturas y continuidades. Desde su origen profesional sociohistórico sus funciones ha estadoasociado con el hacerycon la implementación de políticas sociales y en este sentido, así como lo señala Guerra (2007) "La pregunta sobre el cómo- hacer en trabajo social siempre ha sido una preocupación en el campo profesional y la misma remite a la mistificación del quehacer profesional (Zucherino, Weber Suardiaz, 2014).

El espacio profesional laboral, es un espacio que está en permanente construcción, es complejo y se halla enmarcado en el ámbito de las políticas sociales, que comparte con otras profesiones, y donde confluyen múltiples situaciones laborales por las diversas formas que asume la cuestión social.

Parola (1998) plantea que

El Estado fragmentó la "cuestión social", como si ésta pudiera disecarse y ser abordada en partes, "con lo cual el campo de intervención del trabajo social se constituye a partir de la demanda que se acercaba a las instituciones, pero no por el análisis y contacto con la cuestión social como totalidad que se manifiesta a través de esas demandas parciales.

La definición de un perfil profesional, ha significado una de las preocupaciones importantes en losúltimosaños, atendiendo que el quehacer se ha caracterizado por una diversidad de formas de actuación profesional (Colegio de Trabajadores Sociales de Costa Rica, 1994).
La Federación Internacional de Trabajo Social (2014) en la Conferencia Mundial sobre Trabajo Social, Educación y Desarrollo Social, celebrada en Melbourne (Australia) presenta una nueva definición de Trabajo Social a nivel internacional en donde hace referencia entre otros aspectos que el "El trabajo social es una profesión basada en la práctica".

El Trabajo Social es una disciplina de intervención, que se apoya en la teoría social para comprender los procesos sociales en los que se da la situación problema, para lo cual utiliza distintos conocimientos, técnicas, actividades y diferentes estrategias de intervención.

La dimensión interventiva es parte constitutiva del rol profesional, por lo que el trabajador social debe tener "competencia interventiva, operativa y técnica además de la teórica" (Netto et al., 2002).

La intervención en trabajo social constituye un proceso de construcción social que se genera en el marco de la dinámica sujeto-necesidad como expresión particular de la cuestión social (Rozas Pagaza, 2001).

La intervención no es un episodio natural sino una construcción artificial de un espacio tiempo, de un momento que se constituye desde la perspectiva de diferentes actores de aquellos que solicitan la intervención - instituciones, sujetos individuales y colectivos - y desde el propio sujeto profesional, por lo que la demanda es un proceso artificial (Cazzaniga, 2006). De acuerdo a García Salord (1998, p. 19) "la especificidad profesional es una construcción histórico-social y se estructura en un proceso a través del se delimita el ámbito de relaciones sociales, 
donde se hace necesario determinado tipo de intervención".

No se puede hablar acerca de la metodología y de los métodos de trabajo social sin tener en cuenta el proceso histórico en que fueron surgiendo los mismos.

Se reconocen tres etapas en la historia de las formas de acción social en América Latina que son la Asistencia Social (1925-1940), el Servicio Social (1940 1965) y el Trabajo Social (1965 hasta ahora), identificados con momentos vividos en la historia del Trabajo Social relacionados al asistencialismo, cientificismo y la reconceptualización (Barreix, Castillejos, 2003; Mattus Sepúlveda, 2009).

DesdelaetapadelaReconceptualización y Post-Reconceptualización vivida por la profesión y hasta la actualidad, hay una búsqueda permanente de conformar una identidad propia, que implica competencias teórico-metodológica-técnica. Existe una formación teórica divorciada tanto del quehacer profesional tradicional en cuanto a las nuevas demandas de intervención, ante viejos problemas acumulados y nuevos problemas emergentes en una sociedad cada vez más compleja y cambiante (Mattus Sepúlveda, 2009).

Dada la multiplicidad conceptual en torno a metodologías y métodos en Trabajo Social se sugiere "trascender el carácter prescriptivo, normativo, del método y para dar cuenta de las múltiples dimensiones: contextual, ética, ideológica, epistemológica (Gordillo Forero, 2007).

La instrumentalidad de la profesión está soportado en un conjunto de técnicas e instrumentos que apoyan los procesos de actuación profesional y operan como dispositivos metodológicos de la acción y su uso está vinculado con las concepciones y visiones que se tienen sobre la práctica profesional y la realidad, están relacionadas a los contextos donde se aplican y a los postulados teóricos y metodológicos que lo sustentan (Tonon, 2005).

Olga Vélez Restrepo en su libro Reconfigurando el Trabajo Social (2003) señala que "la emergencia de nuevas problemáticas sociales junto con el derrumbamiento de las tradicionales formas de actuación profesional, planten la necesidad de levantar propuestas alternativas que permitan incidir en el desempeño profesional" (p. 53).

La complejidad de lo social, requiere realizar ajustes en el modo de "hacer" y en lo relativo a los aspectos metodológicos, que deben estar adaptadas a las trasformaciones vividas por la sociedad y construida en diálogos con otros campos del conocimiento (Carballeda, 2012).

El debate actual en América Latina, es la construcción ética y política de la intervención profesional y la adecuación académica, y en este contexto se piensa en el perfil profesional que hay que construir y en los requerimientos propios del mismo, por lo que teniendo en cuenta la diversidad y multiciplicidad de perfiles que existen en el Trabajo Social se hace necesario tener claro cuál es el nuestro (Rosas Pagaza, 2001).

Se presenta los principales resultados obtenidos de una investigación, realizada en el marco de la Maestría en Trabajo Social de la Universidad Americana, con el objetivo de brindar una descripción del escenario del trabajador social en el contexto actual paraguayo, que experimenta cambios políticos, sociales y culturales, abordando aspectos laborales y de actuación profesional que influyen en el carácter de la profesión, ante el desafío de la construcción de un proyecto ético político en concordancia con nuestra realidad.

Cabe señalar que los profesionales que formaron parte de la muestra del estudio se han formado académicamente con planes curriculares muy diferentes a los que actualmente están en vigencia e nuestro país.

\section{Materiales y Métodos}

Estudio observacional, descriptivo, cuantitativo. Se ha realizado una encuesta, en base a un cuestionario autosuministrado con preguntas cerradas y abiertas. Los instrumentos fueron llevados en forma 
personal para su llenado en las diferentes instituciones y también enviados por correo. La muestra conformada por 164 trabajadoras/es sociales, que, si bien no es un estudio representativo, porque se ha utilizado un muestreo no probabilístico de conveniencia, debido a la limitación de no contar con un registro nacional de profesionales, ha pretendido abarcar las distintas áreas donde los profesionales están insertos, quedando tal vez algunas áreas no cubiertas. Está compuesta por profesionales localizados principalmente en Asunción, y en menor porcentaje del interior del país. Los cuestionarios han sido codificados en forma manual y volcados en una base de datos y procesados utilizando el Paquete SPSS. La participación los/ las encuestados/as, ha sido en forma voluntaria, anónima y con el resguardo de la confidencialidad de los datos.

\section{Resultados}

\subsection{Características socio demográficas}

El 91.5\% (150) son del sexo femenino y el 8.5\% (14) del sexo masculino. La profesión del trabajo social en sus orígenes, ha estado históricamente caracterizado por el predominio de las mujeres, este fenómeno fue decreciendo con el trascurso de los años por la incorporación de estudiantes de sexo masculino en la carrera (Figura 1).

El $37.8 \%$ (62) reside y trabaja en Asunción (capital).

\subsection{Perfil Laboral}

El Trabajo Social ha sido de carácter dependiente y esto se ve reflejado en el alto porcentaje de profesionales que están insertos en instituciones. De los profesionales que trabajan en instituciones, el 96.3\%(158/164) lo haceen una institución, mientras que el $33.5 \%$ (55/164) en dos, dando un total de 213 instituciones en las cuales están insertos los profesionales que conforman la muestra. Al respecto, cabe señalar que identidad del Trabajo Social se constituyó en el seno de las instituciones estatales de servicio social, por lo tanto Trabajo Social tuvo -en sus inicios- una práctica profesional exclusivamente institucional y para la atención de las demandas que se acercaban a las mismas (Parola, 1998) (Figura 2).

El 33.8\% (72) trabaja en Ministerios, Secretarías y Programas de Organismos Públicos; $25.3 \%$ (54) en Hospitales; $15.5 \%$ (33) en ONGs/ Fundaciones; 10.8\%(23) en Instituciones Educativas de Nivel Universitario; $4.7 \%$ (10) en Empresas Privadas; el 2.8\% (6) en Instituciones Educativas de Nivel Medio entre las principales (Figura 3).

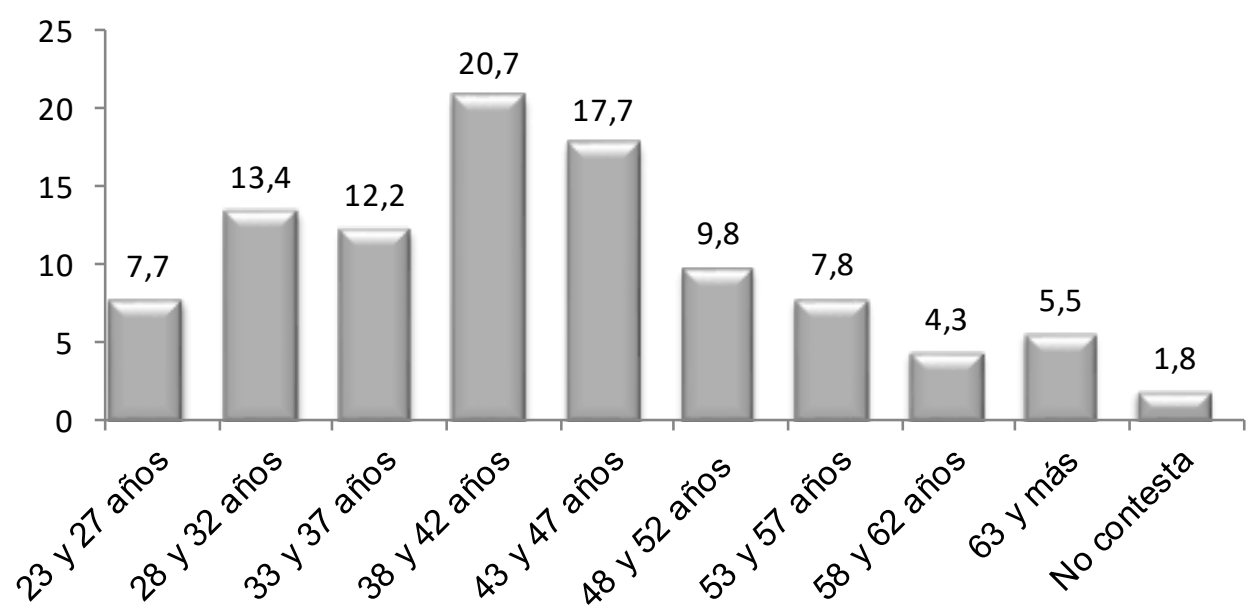

Figura 1. Distribución de los encuestados por grupo etáreo. n=164. 


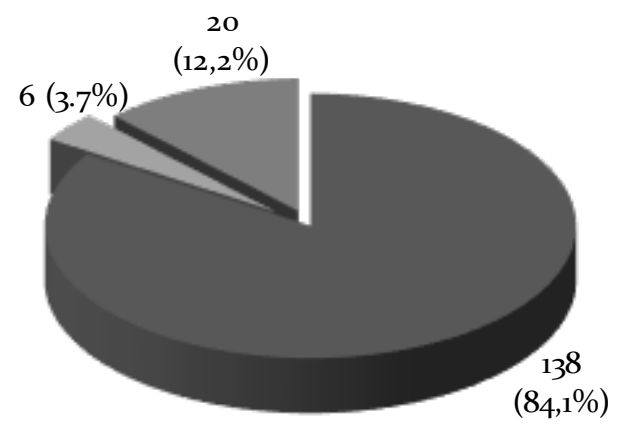

- Institucional $\quad$ Independiente $\quad$ Ambas

Figura 2. Tipo de actividad laboral. $n=164$.

En relación al Departamento o dependencia, el 33.8\% (72), pertenece al de Trabajo Social o Servicio Social, el 7.0\% (15) en la Carrera de Trabajo Social, el 5.2\% (11) en el Dpto. de Desarrollo Humano y Gestión de Talentos, Desarrollo del personal, Bienestar del personal/Dpto. de personal, Dirección de Recursos Humanos Recursos Humanos y Dirección de Relaciones Laborales. El 3.8\% (8) en el Área Social y Dpto. Social, el 3.8\% (8) en el de Proyecto (social), Área de Elaboración de Proyectos y Planificación y proyectos, el $2.8 \%$ (6) en el Equipo Técnico / pedagógico y Área
Pedagógica, el 2,3\% (5) en la Dirección, el $1.9 \%$ (4) entre las principales.

En cuanto a los cargos que ocupan, el 45.0\% (96) el específico a la profesión, el de Trabajador Social o Asistente Social, el $12.7 \%$ (27) el de Jefe/a, el 10.8\% (23) de Coordinador/a, el 7.0\% (15) Docente, el 5.2\% (11) Director/a, el 2.3\% (5) Asesor Técnico e igual porcentaje el de Técnico Social.

Al respecto de la antigüedad, el 8.5\% (18) lleva trabajando en la institución menos de un año; el 37.5\% (80) entre 1 a 6 años; el 20.6\% (44) entre 7 a 12 años; el 15.5\% (33) entre 13 a 18 y 19 años y más $15.1 \%$ (32).

El 12.1\% (26) trabaja entre 2 a 10 horas semanales, el 8.4\% (18) entre 11 a 16 horas, el 8.9\% (19) entre 17 a 25 horas, el 30.1\% (64) entre 26 a 31 horas, el $21.2 \%$ (45) entre 32 a 40 horas, el $4.6 \%$ (10) entre 41 a 49 horas y el $2.3 \%$ (5) 50 y más horas. El 1.4\% (3) sin horario fijo o por resultado. La función pública ha incrementado a 8 horas diarias, 40 semanales la carga horaria, y es así que se aprecia que la mitad trabaja más de 30 horas semanales.

Según un informe elaborado por la Asociación de Asistentes Sociales y/o Trabajadores Sociales del Paraguay, las horas laborales y el salario difieren entre los entes estatales empleadores. Así se tiene que el Ministerio de Salud Pública

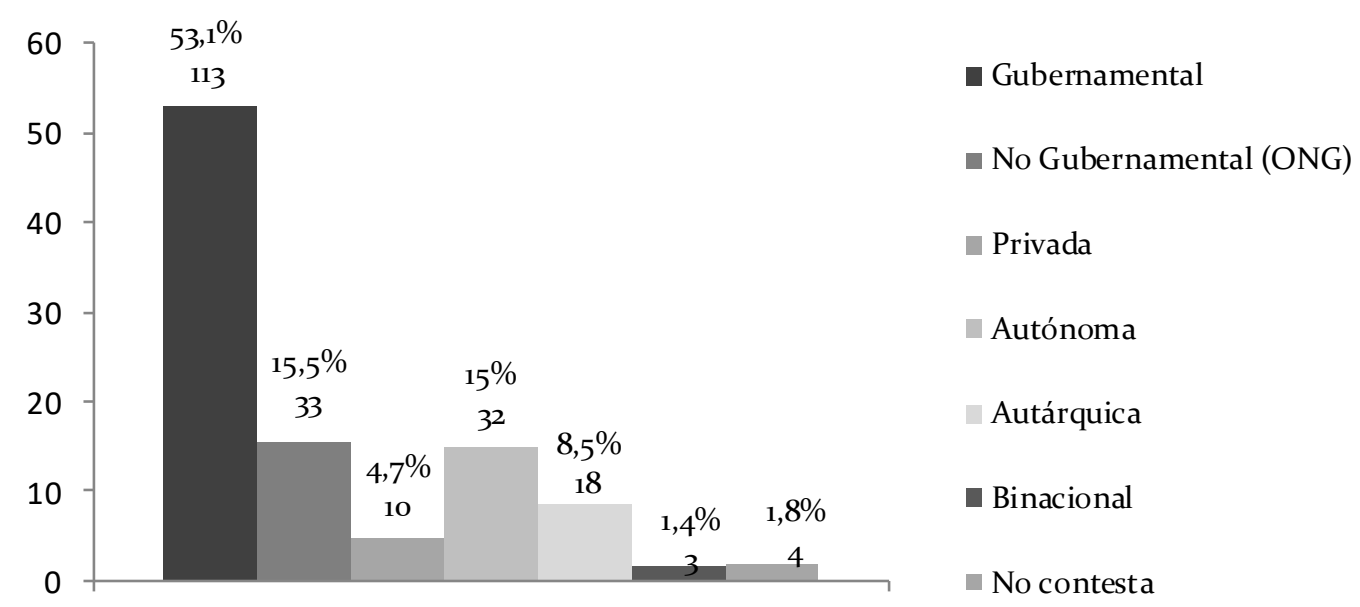

Figura 3. Tipo de Institución u Organización donde trabaja. n=213 instituciones. 
y Bienestar Social, en sus diferentes reparticiones, programas y proyectos, luego de un arduo trabajo de negociación del gremio profesional, se logra la concesión de 6 horas laborales y la equiparación salarial de los Trabajadores Sociales con los demás profesionales (médicos, psicólogos, químicos, entre otros) y con el beneficio de un plus por trabajo de riesgo y bonificaciones por cargo de jefatura.

La Trabajadora Social Heriberta Escobar (2001) señala que otros entes estatales la situación laboral de los Trabajadores Sociales es muy precaria, percibiendo salarios por debajo del mínimo (Ministerio de Educación y Cultura). Así como contratos de apenas de dos meses de duración, sin beneficios adicionales (ONGs, Proyectos financiados por organismos cooperantes e Iglesias). En tanto que en los entes descentralizados las horas de trabajo son de 8 semanales, con salarios por encima del mínimo y beneficios sociales.

El 1.8\% (4) percibe menos deun salario mínimo, el 20.7\% (44) un salario mínimo, el 53.1\% (113), dos salarios mínimos, el 12.7\% (27) tres sueldos mínimos y el 10.3\% (22) cuatro o más.

El 71.3\% (117) ha trabajoanteriormente en otras instituciones y el $28.7 \%$ (47) no lo ha hecho, lo que denota cierta movilidad laboral y confirma que la pertenencia a instituciones sigue siendo preponderante.

De acuerdo la clasificación de Araya y Vega Guzmán (2009), podemos resumir las funciones que asumen los trabajadores sociales encuestados en las siguientes: función de atención directa $23.0 \%$, función de gerencia, administración y planificación de los servicios sociales $13.0 \%$, función docente $5.7 \%$, función preventiva y promocional $4.3 \%$, función de investigación $4.1 \%$, asesoramiento $4.1 \%$, administración de recursos humanos 3.5\%, nexo institucional $2.9 \%$ que corresponde al $60.0 \%$ de las funciones mencionadas y por otro lado, las que corresponde a funciones metodológicas o instrumentales del trabajo social, que dan el $40.0 \%$ entre las que se encuentran las de coordinación/ejecución de actividades, cuyo objetivo prioritario es la realización de actividades programadas para el cambio situacional 14.2\%, investigación y evaluación situacional 9.7\%, organización/planificación de intervenciones $8.6 \%$ y control, monitoreo y evaluación $7.5 \%$.

Si partimos de la idea de que al estar insertos en instituciones se restringe la autonomía, se puede rescatar el hecho de que más de la mitad considera que tiene autonomía para la toma de decisiones, que puede estar asociada al hecho de que en la actualidad ocupa espacios de mayor relevancia (Figura 4 ).

En cuanto a las áreas o ámbitos de intervención, el trabajador social es un profesional capacitado para intervenir en variados campos de actuación y en la práctica se produce un entrecruzamiento con las mismas y al respecto el 51.8\% (85) de los trabajadores sociales encuestado han

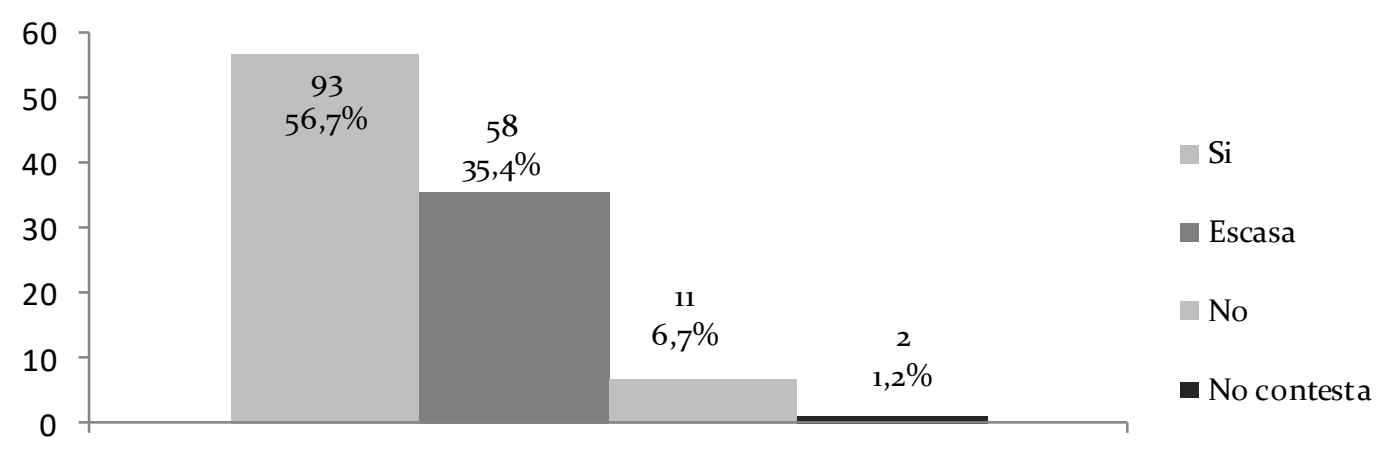

Figura 4. Autonomía para la toma de decisiones. $n=164$. 
señalado en primer lugar que intervienen en el área de la salud, seguido con el $23.2 \%$ (38) en el área de la Educación, el 18.9\% (31) Bienestar Social, el 17.7\% (29) Mediación al igual que en el área de los Servicios Sociales. Asimismo el $15.2 \%$ (25) menciona Docencia Académica, el $12.8 \% \quad$ (21) Seguridad Social, el $\mathbf{1 2 . 2 \%}$ (20) Judicial e igual porcentaje Violencia, el 11.6\% (19) Discapacidad e Investigación, el 8.5\%(14) Laboral-RRHH, el 7.9\% (13) capacitación, el 6.7\% (11) Desarrollo Rural o Comunitario, el 6.1\% (10) Emergencia Social, el 5.5\% (9) Salud Mental, Forense y Vivienda respectivamente entre las principales.

En relación a los sectores de intervención se aprecia que el 55.5\% (91) trabaja con Familias, el 42.1\% (69) con el sector Mujer, el 38.4\% (63) Juventud, el 36.8\% (62) Adultos Mayores, 36.0\% (59) Infancia, $17.1 \%$ (28) Discapacitados (físicos y psíquicos), el 14.6\% (24) Funcionarios Trabajadores dependientes - asegurados funcionarios públicos - personal de salud, el $13.4 \%$ (22) Grupos con necesidades especiales de reinserción, el $11.6 \%$ (19) Grupos en situación de riesgo, el 9.8\% (16) Indígenas y el $6.1 \%$ (10) Estudiantes Universitarios. En menor porcentaje, con el $3.7 \%$ (6) se visualiza el sector de los Drogodependientes, el $2.4 \%$ (4) Políticos, el 1.8\% (3) Pobladores de asentamientos al igual que Consejeros regionales y locales de salud, Grupos vulnerables y Enfermos crónicos terminales.

\subsection{Estrategias de intervención o actuación profesional}

En relación al nivel de actuación, la mayoría de los profesionales $(84.1 \%$, 138) realiza Atención Directa, en el que la intervención se ejecuta en contacto directo con las personas, grupos o colectividades y en reducido porcentaje realiza Atención Indirecta $(91.1 \%, 15)$, que no requiere de ningún contacto. Por otro lado, el 4.9\% (8) actúa en ambos niveles. Por otro lado, el 73.8\% (121) interviene a nivel Micro, que configura una práctica directa de acción
Tabla 1

Tipo de enfoque que utiliza en el proceso de intervención profesional, $n=164$

\begin{tabular}{|c|c|c|}
\hline Enfoque & № & $\%$ \\
\hline Tradicional & 35 & 21.3 \\
\hline Crítico & 97 & 59.1 \\
\hline Ambos & 15 & 9.1 \\
\hline Otros $\left({ }^{*}\right)$ & 4 & 2.4 \\
\hline No sabe & 7 & 4.3 \\
\hline No contesta & 6 & 3.7 \\
\hline Total & 164 & 100.o \\
\hline
\end{tabular}

social y el $15.2 \%$ (25) a nivel Macro, que contempla la planificación del desarrollo y la formulación de políticas sociales. Además, el 4.9\% (8) señala que ambas y el $4.3 \%$ (7) no ha respondido a la pregunta (Tabla 1).

Cabe señalar quea partir del proceso de reconceptualización se ha tratado de superar los enfoques y concepción tradicional sobre la asistencia y el servicio social y el Trabajo social ha entrado en un proceso cuestionador y problematizador tratando de asumir en la sociedad un perfil más crítico y comprometidos con los intereses de los trabajadores y sectores subalternos, que se ha manifestado en una preocupación constante del sentido de su práctica, con el proceso de conocimiento crítico, con la crítica al capitalismo y a las situaciones de injusticia social (Montaño, 2004).

Abordar el tema de los métodos en Trabajo Social no es sencillo. Es importante mencionar que los métodos utilizados por el Trabajo Social fueron cambiando con la historia, los llamados métodos clásicos o tradicionales (Caso, Grupo y Comunidad) han ido surgiendo en un lento proceso y estos posteriormente fueron cuestionados y luego de la llamada etapa de la reconceptualización, se comienza a hablar de la necesidad de elaborar una nueva metodología a partir de considerar 
que existe un método único integrado dependiendo su aplicación de las distintas condicionantes que los movimientos sociales, culturales, económicos, etc.

Al indagar sobre los métodos que adopta en su intervención profesional, el $47.6 \%(78)$ señala que utiliza el método de caso o Individual, el $36.6 \%$ (6o) Integrado o Único el 23.8\% (39), el de Grupo, el 17.7\% (29) de Comunidad.

Se puede apreciar que pese a que se presentan a los métodos tradicionales como obsoletos o históricos, y que más de la mitad utiliza un enfoque crítico, estos siguen siendo utilizados por los profesionales en su intervención profesional.

Cazaniga (1997) señala que si bien no es posible generalizar, existe una tendencia a confundir un abordaje desde la singularidad, con la atención puntual de naturaleza asistencial (gestiones de diverso tipo: alimentos, subsidios, medicamentos, etc.). aunque la creadora del método de caso ella excluye del mismo, las formas de asistencia individual temporaria, al trabajo social subsidiario, por lo que puede explicar que muchos profesionales que realizan este tipo de acción lo relacionan también al método de caso, siendo este método el mencionado por casi la mitad de los encuestados.

En relación a los modelos de intervención, se aborda desde la propuesta de Molina y Romero (2013), que la define no por el tamaño de los mismos sino por la finalidad de la intervención de la profesión y en cómo se construye la relación sujetoobjeto (Figura 5).

La instrumentalidad de la profesión está soportado en un conjunto de técnicas que apoyan los procesos de actuación profesional y operan como dispositivos metodológicos de la acción (Tonon, 2005), al indagar a los trabajadores sociales encuestados sobre las técnicas que utiliza en su intervención profesional, han brindado un total de 414 respuestas, de las cuales el 70.7\% (293) corresponde a técnicas y reconociendo que existe cierta confusión con métodos, actividades, modalidades de actuación y formas de trabajo en las demás respuestas.

El 26.6\% (110) refiere que utiliza la entrevista, en sus variadas formas y cabe señalar que es la técnica por excelencia del Trabajador Social, el $15.0 \% \quad$ (62) la Observación, el $8.7 \%$ (36) la Visita domiciliaria, comunitaria o visita de campo, el 6.5\% (27) Informes, el 3.4\% (14) Investigación, el $2.7 \%$ (11) Ficha Social, el 2.4\% (10) Talleres, el 1.7\% (7) Grupos de discusión y Grupos focales, el 1.4\% (6) Técnicas documentales ( Recopilación documental- investigación documental y el $1.0 \%$ (4) la Historia Social. Por otro lado señalaron Charlas (9, 2.2\%), Proyecto $(7,1.7 \%)$, Trabajo con Grupos (7, 1.7\%), Diagnóstico (6, 1.4\%), Técnicas Participativas (5, 1.2\%), Evaluación (5, 1.2\%), Comunidad (4, 1.0\%), Reuniones (3,0.7\%), Trabajo en equipo (3, 0.7\%), Planificación (de cursos, de evaluación, de acciones)(3,

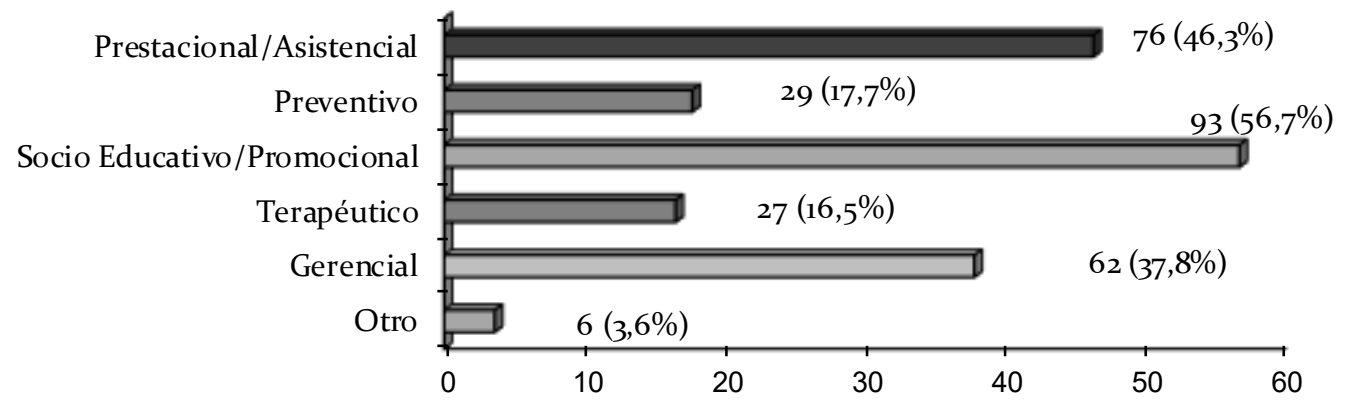

Figura 5. Modelos de Intervención Profesional. n=164.

(*) Otro: Pericial (5) - Evaluativo (1) 
$0.7 \%)$, Sistematización (3,0.7\%), Análisis institucional $(3,0.7 \%)$, Mesas de trabajo - mesa (2, 0.5) Técnicas de educación popular $(2,0.5 \%)$, Orientación $(2,0.5 \%)$, Contención (2, 0.5\%), Monitoreo(2, 0.5\%) y Análisis (2, 0.5\%)

Se define a las actividades entendidas como el conjunto de tareas propias del profesional de trabajo social y al respecto se puede apreciar que son innumerables las que realiza, algunas comunes para todas las áreas de intervención y otras específicas acorde a las funciones que cumple.

Entre las actividades que efectúan con mayor frecuencia se destacan las Entrevistas (9.1\%, 58), Elaboración de informes relacionados con la situación socioeconómica, familiar, pericial, socio laboral, victimológico y socio ambientales $(7.5 \%$, 47), Atención directa, acompañamiento y Seguimientos de casos de usuarios (6.1\%, 39), Visitas Domiciliarias5.9\%, 39), Intervención en conflictos laborales y acompañamiento en situación problema de funcionarios $(5.5 \%, 35)$, Planificación o Formulación y ejecución de programas, proyectos o planes $(5.0 \%, 32)$, Articulación - contacto Interinstitucional $(5.0 \%, 32)$, Orientación e Información (4.7\%, 30),
Charlas, talleres de capacitación (4.6\%, 29), Elaboración de informes (3.6\%, 23), Organización y Participación en reuniones (3.2\%, 23), Inherentes a la docencia (2.7\%, 17), Supervisión y monitoreo de actividades /proyectos/ planes y programas $(2.5 \%, 16)$.

Por otro lado, Trabajo en Equipo técnico-interdisciplinario $\quad(2.9 \%, 13)$, Organización de eventos, seminarios, talleres, actividades (1.6\%, 10), Ejecución del plan operativo/ programas/proyectos (1.6\%, 10), Visita Institucional (1.1\%, 7), Desarrollo comunitario/ actividades de desarrollo de la comunidad-gestionesdedesarrollocomunal $(1.1 \%, 7)$, Investigaciones - censo- estudios socioeconómicos comparativos - diseño y ejecución de proyectos de investigación $(1.1 \%, 7)$,Observación $(0.9 \%, 6)$, Gerenciales $(0.8 \%, 5)$, Derivación de casos (o.8\%, 5), Visita comunitaria o de campo (o.8\%, 5) y Coordinación de actividades-accionesequipo interdisciplinario- Programas - centro comunitario $(0.8 \%, 5)$ entre las principales (Figura 6).

Mencionando específicamente la falta derecursosparaintervenir, lapocavaloración o reconocimiento de la profesión, falta de autonomía para la toma de decisiones, e poco espacio del trabajador social en la toma

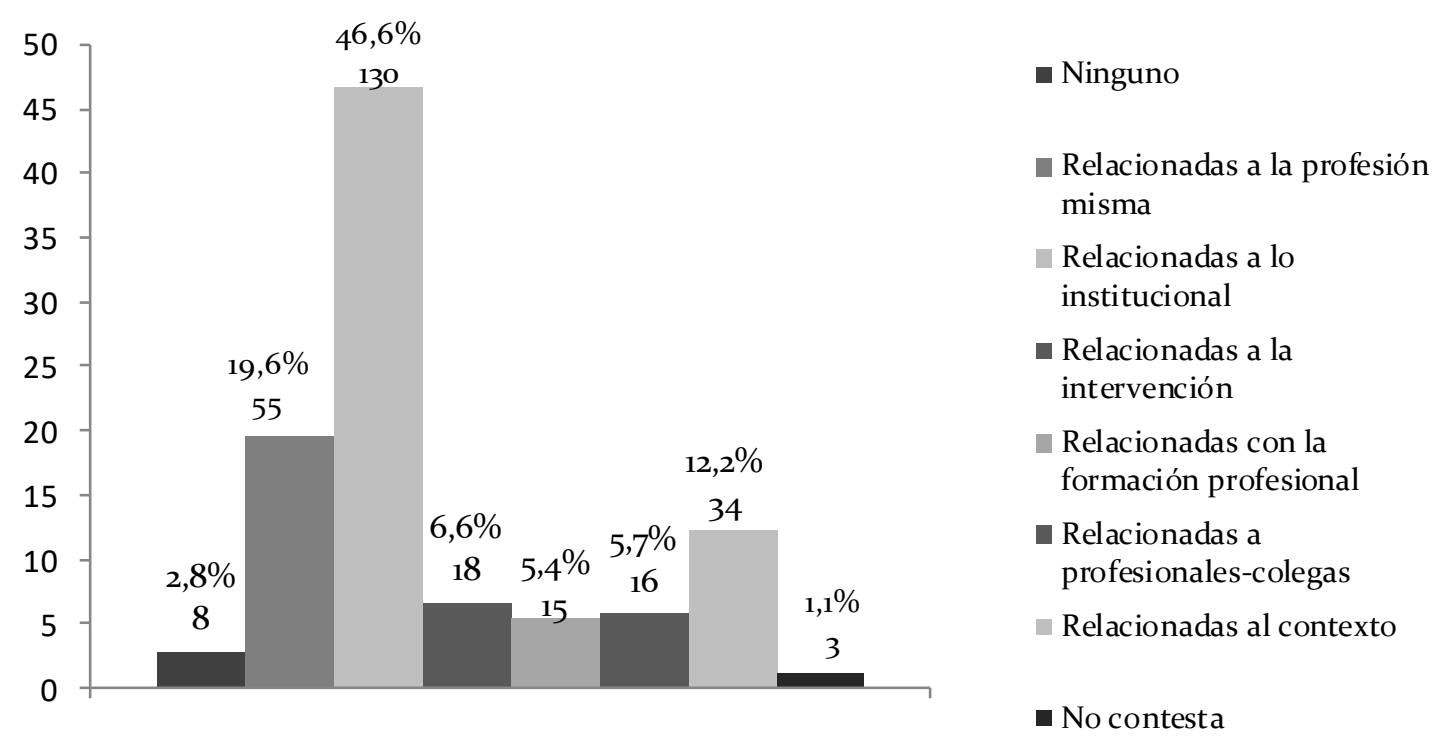

Figura 6. Dificultades que enfrenta en su quehacer profesional. $n=279$ respuestas. 
de decisiones, la burocracia institucional, poco conocimiento y confusión acerca de la profesión, el trabajo interinstitucional, el de trabajar en equipos, la lucha por el espacio profesional, la falta de valoración económica de la profesión, falta de espíritu de grupo y competencia entre colegas y sobrecarga laboral por falta de recursos humanos entre otras.

El 6.6\% (12) señala que realiza la intervención profesional en base a la corriente ideológica crítica o Marxismo e igual porcentaje con el Enfoque de derecho, el 4.4\% (8) Socialismo, el 3.8\% (7) Social democracia, el 3.3\% (6) en base a la Corriente positivista, el 2.7\% (5) Humanista y el $2.7 \%$ (5) bajo la perspectiva teórica del constructivismo entre la principales. Cabe señalar que el $7.1 \%$ (13) ha respondido que no tiene ninguna influencia ideológica, el $11.5 \%$ (21) no sabe, el $28.6 \%$ (52) no ha sabido responder a la pregunta y además han mencionado que es difícil saberlo o no entiende la pregunta (2, 1.0\%), lo que refleja que no se tiene claridad al respecto y que ha sido un tema poco abordado en el ámbito profesional.

Eltrabajoenequipointerdisciplinario, constituye un elemento fundamental en el quehacer cotidiano del Trabajo Social, se observa que la mayoría, 81.1\% (133) participa en equipos interdisciplinarios y el $18.9 \%$ (31) no lo hace. La colega María del Carmen Barronco Expósito (2004) al respecto manifiesta que "la intervención profesional se debe realizar desde una perspectiva globalizadora, intradisciplinar e interdisciplinar, para profundizar y dar una respuesta más efectiva a las situaciones complejas que caracterizan la realidad social". (p. 84)

En relación a la percepción de un proyecto ético político definido, solo el $17.1 \%$ (29) lo ha estimado que si existe, pero el 59.8\% (98) no y el $22.6 \%$ (37) no lo sabe.

\section{Conclusiones}

Respecto a la situación laboral, la gran mayoría se halla trabajando en una institución y un bajo porcentaje lo ejerce de manera independiente. Insertos laboralmente en 92 instituciones y un número importante en dos instituciones, dando un total de 213 instituciones referidas.

El Trabajo Social ha sido siempre de carácter dependiente y esto se ve reflejado en el porcentaje de encuestados que están insertos en instituciones, no obstante vemos que está surgiendo la modalidad de trabajo independiente, debido a que se está en aumento el llamado a concurso para consultorías, contrato por proyectos etc. que si bien brinda mayor autonomía a los profesionales y mejor remuneración económica, no da estabilidad laboral. El sector público estatal es el principal empleador y aglutina a un poco más de la mitad de las/os encuestadas/os, insertos principalmente en las estructuras centrales del Estado; se observa escasa participación en las municipalidades y gobernaciones. El sector de Organizaciones No Gubernamentales y Asociaciones Civiles es un espacio en crecimiento y el sector privado empresarial involucra a un sector minoritario del colectivo profesional.

Más de la mitad tiene una antigüedad de hasta de 10 años y la otra mitad llega a los 20 años. La mayoría cumple entre 30 y 40 horas semanales. Un poco más de la mitad recibe el equivalente a dos salarios mínimos y solo el 10\% cuatro o más. Un poco más de la mitad considera que tiene autonomía para la toma de decisiones y si partimos de la idea de que al estar insertos en instituciones se restringe la autonomía, se puede rescatar el hecho de que más de la mitad considera que tiene autonomía para la toma de decisiones, que puede estar asociada al hecho de que en la actualidad ocupa espacios de mayor relevancia

Las principales funciones que asumen los trabajadores sociales encuestados en las siguientes: Atención Directa, Gerencial, Administración y Planificación de los Servicios Sociales, Función Docente, Función preventiva y 
Promocional, Función de investigación, Asesoramiento, Administración de recursos humanos, Nexo institucional y funciones metodológica o instrumentales entre las que se encuentran las de Coordinación / ejecución de actividades, Investigación y evaluación situacional, Organización / planificación de intervenciones y Control, monitoreo y evaluación.

En relación a las particularidades que incumben a la actuación profesional, se puede concluir que hoy día, las características que asume su práctica hacen que su campo de acción sea muy amplio y variado, se identifica un amplio listado que puede abarcar más de los mencionados por los encuestados.

Se observa que la mitad de los mismos se desempeñan en el campo de la salud, siendo este uno de los campos de mayor y más antigua implantación del trabajo social y que ha cobrado importancia El segundo campo es el educativo seguido de Bienestar Social, la mediación y los servicios sociales.

En cuanto a los sectores de actuación profesional, se trabaja con familias, mujeres, jóvenes, adultos mayores, infancia, discapacitados y funcionarios, interviniendo a nivel micro que configura una práctica directa y menor escala a nivel Macro, que contempla la planificación del desarrollo y la formulación de políticas sociales y mayoritariamente con un modelo socio educativo promocional, seguido del asistencial o prestacional.

Cabe señalar que si bien tradicionalmente se le asigna a la profesión un rol de implementador de políticas, hoy se presenta el gran desafío de ser protagonista de la elaboración de las mismas, convirtiéndose en un ámbito privilegiado de actuación profesional, que se está efectivizando gracias a que los trabajadores sociales están ocupando espacios de poder en diversas instituciones públicas, desde donde se formulan las políticas sociales, ámbito que se encuentra trabajando junto a otras profesiones.

El Trabajo Social contemporáneo propone una intervención profesional con un enfoque crítico, enfoque referido por más de la mitad, pero que se contradice con el alto porcentaje de profesionales que señalaron que su actuación se enmarca en una práctica con métodos tradicionales (caso o individual, grupo, comunidad). Se detecta cierta confusión con métodos, actividades, modalidades de actuación y formas de trabajo. La mayoría de los profesionales participa en equipos interdisciplinarios.

El tema de la corriente ideológica en la intervención profesional ha sido poco discutida en los ámbitos académicos antes del cambio curricular actual, lo que se ve reflejado en que la mayoría no tiene claridad al respecto porque fueron formados con diferentes mallas curriculares.

Los profesionales encuestados señalan que son numerosas las dificultades que enfrenta en su quehacer profesional, casi la mitad refiere las relacionadas con lo institucional, seguido de aspectos que atañen a la profesión misma, al contexto, a la intervención misma, en la relación entre los profesionales-colegas y relacionadas con la formación profesional.

Pese al desafío que ha tenido tanto la academia como la agrupación gremial para delinear una Postura Ética Política un bajo porcentaje percibe la existencia de un proyecto ético político en el país.

Se hace necesario crear espacios de reflexión para debatir en relación a teorías, metodologías, técnicas e instrumentos de la profesión.

Esfundamentalqueel/laTrabajador/a Social tenga bien definido cuál es su papel y como lo va a desempeñar, para el logro de objetivos que son muchas veces comunes para profesionales de otras disciplinas y este papel debe estar determinado por la naturaleza y características de la profesión.

El espacio laboral del trabajo social es muy complejo porque existen diversas profesiones que trabajan con la cuestión social, que exige el desarrollo de habilidades y destrezas propias que den cuenta de los 
desafíos y exigencias planteadas por la realidad y por las diversas formas que sume la cuestión social y sus expresiones en sus diversos campos de actuación de los sujetos individuales y colectivos.

\section{Referencias Bibliográficas}

Barreix, J. \& Castillejos Bedwell, S. (2003). Metodología y Método en Trabajo Social. Buenos Aires: Espacio

Barronco Expósito, M. C. (2004). La intervención en trabajo social desde la calidad integrada. Alternativas. Cuadernos de Trabajo Social, (12), 79102. Reuperado de http://hdl.handle. net/10045/5592

Carballeda, A. J. (2012). La intervención en los social/exclusión e intervención en los nuevos escenarios sociales. Buenos Aires: Paidós.

Cazzaniga, S. (1997). Trabajo Social: Metodología. El abordaje desde la singularidad. Universidad Nacional de Entre Ríos (UNER). Facultad de Trabajo Social. Recuperado de www.margen. org/catedras/Caso\%2oSusana\%2o Cazaniga.do

Cazzaniga, S. (2006). Reflexiones sobre la ideología, la ética y la política en Trabajo Social. Recuperado de www.fcp.uncu.edu.ar/.../ ReflexionessobreeticaeideologiaenTS.doc

Colegio de Trabajadores Sociales de Costa Rica. Comisión Perfil Profesional. (1994).

Federación Internacional de Trabajadores Sociales (FITS). (2014). Asociación Internacional de Escuelas de Trabajo Social (AIETS). Nueva definición global de Trabajo Social. Recuperado de http://trabajosocialencuenca. blogs pot.com/2014/o / nueva definicion-global-de-trabajo.html

Fuentes, M.P. \& Cruz, V. (2014). Lo Metodológico en Trabajo Social. Desafíos frente a la simplificación $e$ instrumentalización de lo social. Facultad de Trabajo Social. La Plata: Universidad Nacional de la Plata.
García Salord, S. (1998). Especificidad y rol en trabajo social. Buenos Aires: Editorial Lumen/Hvmanitas.

Gordillo Forero, N. (2007) Metodología, método y propuestas metodológicas en Trabajo Social. Revista Tendencia $\mathcal{E}$ Retos, (12), 119-135. Recuperado de https://dialnet.unirioja.es/descarga/ articulo/4929312.pd

Guerra, Y. (2007). A instrumentalidade do Serviço Social. Saõ Paulo: Editora Cortez

Matus Sepúlveda, T. (2009). Principales tendencias o corrientes del trabajo social. Revista Electrónica de Trabajo Social. Recuperado de http:// serviciosocialipp.bligoo.com/content/ view/191869/Principales-tendenciaso-corrientes-del-Trabajo-Social.html

Molina, M. L. \& Romero, M. C. (2013). Modelos de Intervención asistencial, socioeducativo y terapéutico en trabajo social. San José: Editorial de la Universidad de San José.

Montaño, C. (2004). Hacia la construcción del Proyecto Ético-Político Profesional Crítico. Ponencia presentada en el XVIII Seminario Latinoamericano de Escuelas de Trabajo Social (ALAETS). Costa Rica, Julio de 2004. Recuperado de http://www.ts.ucr.ac.cr/binarios/ congresos/reg/slets/slets-018-045.pdf

Netto, J. P., Parra, G., Carballeda, J., Aquín, N., Robirosa, M., Elías, M. F., Eroles, C. \& Clemente, A. (2002). Nuevos Escenarios y práctica profesional. Una mirada crítica desde el Trabajo Social. Buenos Aires: Espacio.

Parola, R. (1998). Medios para la producción de conocimiento en trabajo social: las problemáticas de la praxis social, la investigación social y la sistematización. Ponencia presentada en el XVI Congreso Latinoamericano de Escuelas de Trabajo Social. Santiago de Chile. Recuperado de http://www. ts.ucr.ac.cr/binarios/congresos/reg/ slets/slets-o16-o8o.pdf

Perfil Profesional del quehacer del(a) 
trabajador(a) social. San José. Recuperado de http://www.ts.ucr. ac.cr/binarios/pela/pl-ooo396.pdf

Rozas Pagaza, M (2001). La intervención Profesional en relación con la cuestión social. El caso del Trabajo Social. Buenos Aires: Espacio.

Tonon, G. (Ed.). (2005). Las técnicas de actuación profesional del Trabajo Social. Buenos Aires: Editorial Espacio

Vélez Restrepo, O. L. (2003). Reconfigurando el trabajo social. Perspectivas y tendencias contemporáneas. Buenos Aires: Editorial Espacio
Zucherino, L. \& Weber Suardiaz, C. (2014). Tendencias teórico-metodológicas en Trabajo Social: la tensión entre teoricismo y pragmatismo. En: M. Fuentes \& V. Cruz, (Ed.), Lo Metodológico en Trabajo Social: Desafíos frente a la simplificación e instrumentalización de lo social (p. 16). La Plata: Universidad de la Plata. 